\title{
POPULATION STUDY ARTICLE Childhood cardiovascular health and subfertility: the Bogalusa Heart Study
}

\author{
Yiping Wang ${ }^{1}$, Xu Xiong ${ }^{1}$, Lydia Bazzano ${ }^{1}$ and Emily W. Harville ${ }^{1}$
}

\begin{abstract}
BACKGROUND: Although childhood cardiovascular risk can contribute to adult cardiovascular disease, and fertility and adult cardiovascular health are linked, the association between early-life cardiovascular risk and female infertility has not been studied. METHODS: A total of 1799 women participated in the Babies substudy of the Bogalusa Heart Study. Systolic blood pressure (SBP), diastolic blood pressure (DBP), low-density lipoprotein (LDL), high-density lipoprotein (HDL), triglycerides, glucose, and insulin were age-standardized and examined as predictors of self-reported fertility difficulties using multivariable logistic regression with adjustment for confounders. Polycystic ovarian syndrome (PCOS) was assessed via a report of diagnosis and symptoms, using a validated questionnaire.

RESULTS: Women with a history of PCOS were more likely to report fertility difficulties. Childhood and adolescent cardiovascular risk factors were generally not associated with fertility indicators, although childhood LDL (aOR 1.38 per one-SD increase, 0.97-1.96) and total cholesterol (aOR 1.49, 1.06-2.11) were raised in those who never became pregnant. Pre-pregnancy risk SBP (overall fertility, aOR 1.49, 1.00-2.23) and glucose levels (ever tried but unable, aOR 2.65, 1.39-5.06) were associated with an increased risk of some infertility indicators. These results were largely unaffected by exclusion of women with PCOS.

CONCLUSION: Some childhood and pre-pregnancy cardiovascular risk factors are associated with adult subfertility.
\end{abstract}

Pediatric Research (2018) 84:625-631; https://doi.org/10.1038/s41390-018-0032-x

\section{INTRODUCTION}

Infertility, the inability to get pregnant, is a common condition that affects about $12 \%$ of child-bearing age women in the United States. ${ }^{1}$ However, the determinants of infertility are poorly understood. Although a number of risk factors are known (especially age, smoking, and high or low weight ${ }^{2}$ ), the underlying etiology of infertility among $\sim 15-30 \%$ of couples cannot be unexplained after their diagnostic workup. ${ }^{3,4}$ Even if the underlying medical etiology is known, knowledge of the proximal biological pathway may not be of much use in preventing or treating the condition. Obesity in adulthood, ${ }^{5}$ and even childhood, ${ }^{6}$ has been associated with infertility; associations with waist circumference and waist-hip ratio are less clear., ${ }^{7,8}$ Other cardiovascular risk factors have been studied to a lesser extent. A few studies have suggested that abnormal total cholesterol, LDL, $H D L$, and triglycerides are all associated with reduced fecundability or clinical infertility, partially though not completely due to associations with BMI. ${ }^{9-11}$ Infertile women may be at higher risk for later cardiovascular disease (CVD) ${ }^{12,13}$ which might indicate a shared etiology. However, although cardiovascular risk factors in childhood can contribute to the development of CVD in adulthood, $^{14,15}$ our literature review did not find any previous assessment of the association between cardiovascular risk factors in early life and female infertility.

The present study investigated the association between childhood cardiovascular risk factors and subfertility. Hypothetically, cardiovascular risk factors at an early age could contribute to subfertility later, thus offering a new plausible approach for infertility prevention. We also considered the role of polycystic ovarian syndrome (PCOS), a chronic, lifelong endocrine disorder with correlations both with infertility ${ }^{16,17}$ and cardiometabolic disease, ${ }^{18-21}$ in the relationship between early-life cardiovascular risk factors and fertility.

\section{METHODS}

\section{Study population}

The Bogalusa Heart Study (BHS) is a biracial (65\% White and 35\% Black) longitudinal epidemiological study of the early natural history of CVD. The BHS, founded by Dr. Gerald S. Berenson in 1973 , conducted serial observations from child to adulthood in the semirural community of Bogalusa, Louisiana, USA. ${ }^{22}$ Initial study participants aged 3-18 were enrolled from schools in 1973 and additional participants were added in the study over time. Data collection occurred approximately every 2 years and 5 years for children and adults, respectively. These cross-sectional studies were combined to create the overall BHS study population.

The Bogalusa Babies sub-study (BBS) was started in May 2013 to investigate the relation between cardiovascular risk factors in childhood with female reproductive outcomes. Female study participants who had at least one visit in BHS prior to 18-years old were eligible to be included in this study $(n=5914)$, regardless of whether they had been pregnant. Of these, 1804 participated in BBS from May 2013 to November 2017. The most common reason for not participating was that they could not be located or contacted. Compared with the rest of the study cohort, participants in the Babies study had participated more often and more recently in the study, had a slightly older age at first visit (10.0 vs. 9.4, $p<0.01)$, and were more likely to be black (41 vs. $34 \%, p<0.01)$. When standardized for age, BMI and blood

1Department of Epidemiology, School of Public Health and Tropical Medicine, Tulane University, New Orleans, LA, USA
Correspondence: Emily W. Harville (eharvill@tulane.edu)

Received: 28 November 2017 Revised: 9 March 2018 Accepted: 15 March 2018

Published online: 13 June 2018 
Table 1. Characteristics of the study population by fertility outcome

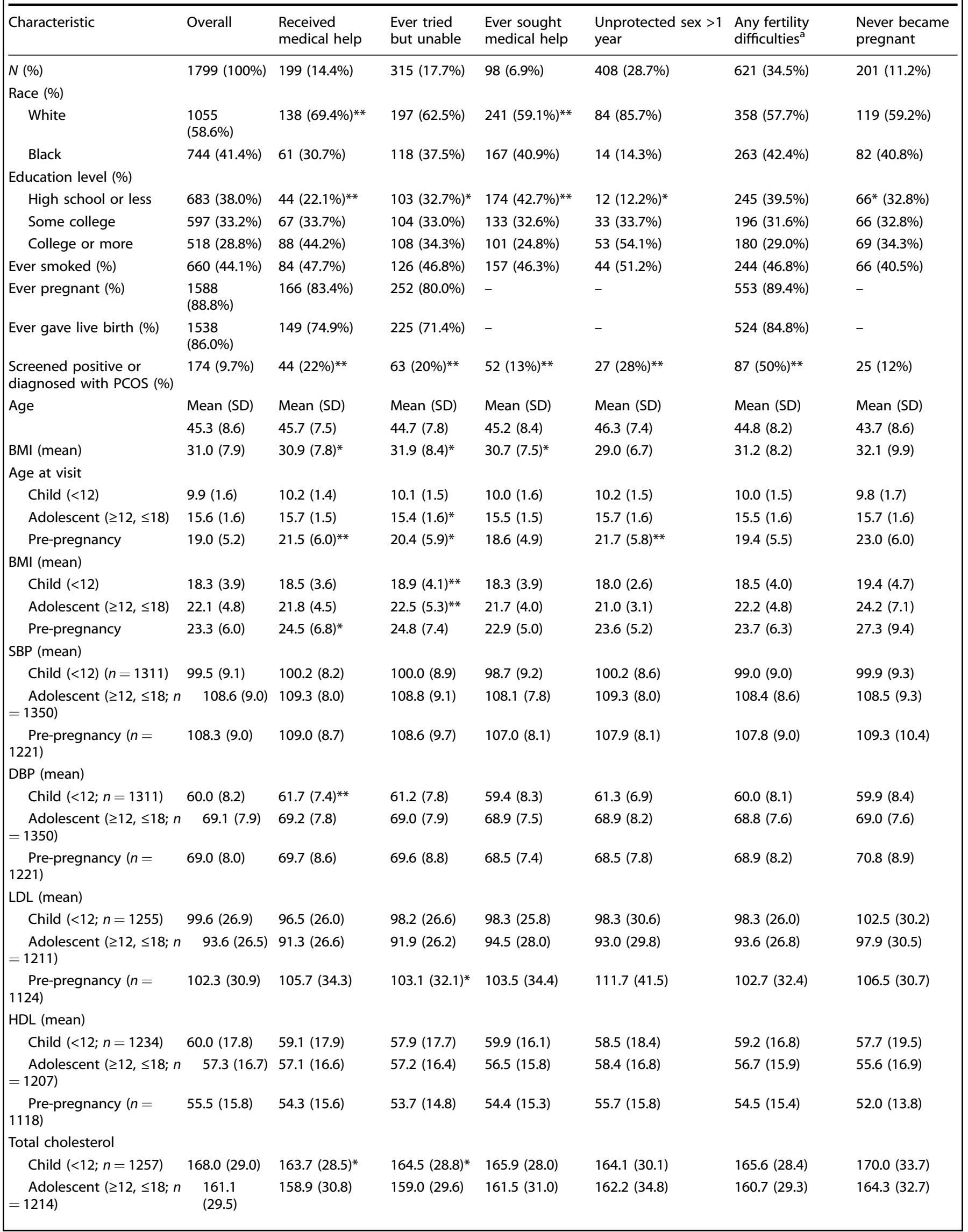




\begin{tabular}{|c|c|c|c|c|c|c|c|}
\hline Characteristic & Overall & $\begin{array}{l}\text { Received } \\
\text { medical help }\end{array}$ & $\begin{array}{l}\text { Ever tried } \\
\text { but unable }\end{array}$ & $\begin{array}{l}\text { Ever sought } \\
\text { medical help }\end{array}$ & $\begin{array}{l}\text { Unprotected sex }>1 \\
\text { year }\end{array}$ & $\begin{array}{l}\text { Any fertility } \\
\text { difficulties }^{\mathrm{a}}\end{array}$ & $\begin{array}{l}\text { Never became } \\
\text { pregnant }\end{array}$ \\
\hline \multicolumn{8}{|l|}{ Triglyceride (median, IQR) } \\
\hline Child $(<12 ; n=1218)$ & $62.0(34.5)$ & $63.4(39.0)$ & $64.8(40.0)$ & $65.0(36.0)$ & $64.0(32.0)$ & $64.0(34.5)$ & $69.0(40.5)$ \\
\hline $\begin{array}{l}\text { Pre-pregnancy }(n= \\
1108)\end{array}$ & $70.0(44.8)$ & $71.5(40.5)$ & $69.0(41.5)$ & $68.0(47.0)$ & $72.0(43.0)$ & $70.5(43.8)$ & $72.3(42.5)$ \\
\hline \multicolumn{8}{|l|}{ Glucose (mean) } \\
\hline Child $(<12 ; n=1016)$ & $82.3(8.2)$ & $82.9(7.8)$ & $82.0(8.4)$ & $83.4(9.1)$ & $83.1(6.9)$ & $82.8(8.2)$ & $82.3(8.1)$ \\
\hline $\begin{aligned} & \text { Adolescent }(\geq 12, \leq 18 ; n \\
&=1121)\end{aligned}$ & $82.5(8.4)$ & $82.8(7.4)$ & $83.5(7.6)$ & $81.9(8.9)$ & $81.4(7.7)$ & $82.4(8.5)$ & $83.2(8.7)$ \\
\hline Child $(<12 ; n=701)$ & $9.0(8.0)$ & $11.0(8.0)$ & $10.0(9.6)$ & $10.0(7.0)$ & $9.0(8.0)$ & $9.4(8.0)$ & $10.0(8.6)$ \\
\hline $\begin{aligned} & \text { Adolescent }(\geq 12, \leq 18 ; n \\
= & 781)\end{aligned}$ & 11.0 & $11.0(9.0)$ & $12.0(8.7)$ & $11.0(5.0)$ & $11.0(7.0)$ & $11.0(7.9)$ & $12.0(10.5)$ \\
\hline $\begin{array}{l}\text { Pre-pregnancy }(n= \\
879)\end{array}$ & $10.0(7.0)$ & $10.5(9.0)$ & $11.0(9.2)$ & $9.0(7.0)$ & $11.0(7.0)$ & $11.0(7.8)$ & $10.0(8.4)$ \\
\hline
\end{tabular}

pressure were not different for included and excluded participants; with a few exceptions (statistically lower childhood triglycerides $(p=0.01)$ and total adolescent cholesterol $(p=$ $0.05)$ ), neither were lipid levels. A total of 1799 had information on either infertility-specific question or number of total pregnancies. The number included in each individual analysis depended on the amount of data available for the individual risk factors (Table 1).

\section{Cardiovascular risk factors}

Blood pressure was measured on the right arm of the subjects in a relaxed, sitting position. The length and circumference of the arms were measured during the examination for proper cuff size. Systolic blood pressure (SBP) and diastolic blood pressure (DBP) levels were measured by using mercury sphygmomanometers. The average of six replicate measurements was used in all analyses, taken by each of two trained examiners who were blinded to each other's readings. Serum lipoprotein cholesterols, including high-density lipoprotein (HDL) and low-density lipoprotein (LDL) cholesterol, were analyzed by using a combination of heparin calcium precipitation and agar-agarose gel electrophoresis procedures. Serum triglycerides level was measured with a Technicon Auto Analyzer II according to the laboratory manual of the Lipid Research Clinics Program during 1973-1986 and was determined by enzymatic procedures since 1987, both of which met the performance requirements of the lipid-standardization program of the Centers for Disease Control and Prevention. From 1981 to 1991, plasma glucose was measured by a glucose oxidase method using a Beckman Glucose Analyzer (Beckman Instruments, Palo Alto, CA). Since then, it has been measured enzymatically as part of a multichemistry (SMA20) profile.

A radioimmunoassay kit was used to measure plasma insulin (Phadebas Insulin Kit, Pharmacia Diagnostics, Piscataway, NJ).

For childhood, periods of growth were divided into two stages, childhood (age $<12$ ) and adolescence $(12 \leq$ age $\leq 18)$. If a participant had more than one measurement in a given period, the measurement in the last visit in a period was used. For pre- pregnancy cardiovascular risk factors, measures in the last visit prior to pregnancy in adolescence and adulthood were used among women who had ever been pregnant; among neverpregnant women, the measures in the last visit after age 18 and before age 32.1 (the mean age of the last visit among those who got pregnant plus 5 years) were used. For lipids, glucose, and insulin, the measurement taken fasting that fit of these requirements was used; between 1 and $10 \%$ of the measures at any given time point were non-fasting (with childhood visits less likely to be fasting).

Adult fertility measures

During the interview in BBS, the participants were asked several fertility-related questions; four self-reported questions are included in this analysis. Women were asked whether they had taken any fertility drugs or received any medical procedures from a doctor, nurse, or other health care worker to help them get pregnant; ever tried to become pregnant and were not able to; or had ever been to a doctor to get help in getting pregnant. Women who got pregnant were asked their time to pregnancy (TTP); TTP $>12$ months was considered a difficulty. Women were defined overall as having any fertility difficulties if they answered "yes" to any one of these questions, and could be included in one or more of them. Additionally, ever getting pregnant was used as an indicator of fertility. Although self-report is not perfect, it provides a reasonable estimate of fertility difficulties with high specificity. ${ }^{23,24}$ Specifically, use of fertility treatment, long TTP, and occurrence of pregnancy are well-reported, ${ }^{24-26}$ with exact TTP being less wellreported. ${ }^{27}$

\section{Covariates}

Age was calculated from participant's date of birth and interview. Race (White/Black) was recorded at the initial BHS visit. The highest level of education completed was categorized as high school or less, some college, and college or more. Current height was measured in the visit at age 16 or older; ${ }^{28}$ if the height value was not available, the multiplier method was used to estimate 
Table 2. Childhood cardiovascular risk factors by time period and reported fertility difficulties in adulthood

\begin{tabular}{|c|c|c|c|c|c|c|c|c|c|c|c|c|}
\hline Cardiovascular risk factors & $\mathrm{OR}^{\mathrm{a}}$ & $95 \% \mathrm{Cl}$ & $\mathrm{OR}^{\mathrm{a}}$ & $95 \% \mathrm{Cl}$ & $\mathrm{OR}^{\mathrm{a}}$ & $95 \% \mathrm{Cl}$ & $\mathrm{OR}^{\mathrm{a}}$ & $95 \% \mathrm{Cl}$ & $\mathrm{OR}^{\mathrm{a}}$ & $95 \% \mathrm{Cl}$ & $\mathrm{OR}^{\mathrm{a}}$ & $95 \% \mathrm{Cl}$ \\
\hline \multicolumn{13}{|l|}{ SBP } \\
\hline Child $(<12)$ & 1.04 & $0.74-1.47$ & 0.92 & $0.69-1.22$ & 0.94 & $0.71-1.23$ & 0.94 & $0.59-1.50$ & 0.88 & $0.70-1.11$ & 0.95 & $0.68-1.34$ \\
\hline Adolescent $(\geq 12,<18)$ & 1.33 & $0.93-1.90$ & 1.27 & $0.94-1.70$ & 0.93 & $0.71-1.23$ & 1.50 & $0.93-2.42$ & 1.03 & $0.82-1.30$ & 1.06 & $0.72-1.55$ \\
\hline Adolescent $(\geq 12,<18)$ & 0.94 & $0.66-1.34$ & 1.10 & $0.82-1.48$ & 0.88 & $0.67-1.15$ & 1.09 & $0.69-1.73$ & 0.93 & $0.74-1.18$ & 1.01 & $0.69-1.48$ \\
\hline \multicolumn{13}{|l|}{ LDL } \\
\hline Child $(<12)$ & 1.09 & $0.77-1.55$ & 1.16 & $0.87-1.53$ & 1.24 & $0.93-1.64$ & 1.33 & $0.81-2.19$ & 1.14 & $0.90-1.44$ & 1.38 & $0.97-1.96$ \\
\hline Adolescent $(\geq 12,<18)$ & 0.98 & $0.64-1.49$ & 0.88 & $0.63-1.24$ & 1.04 & $0.75-1.42$ & 1.19 & $0.70-2.05$ & 0.97 & $0.74-1.27$ & 1.33 & $0.86-2.07$ \\
\hline \multicolumn{13}{|l|}{ HDL } \\
\hline Child $(<12)$ & 0.87 & $0.62-1.22$ & 0.91 & $0.69-1.20$ & 1.16 & $0.88-1.53$ & 0.76 & $0.46-1.25$ & 1.05 & $0.83-1.32$ & 1.49 & $1.06-2.11$ \\
\hline Adolescent $(\geq 12,<18)$ & 0.97 & $0.64-1.46$ & 0.81 & $0.58-1.14$ & 0.83 & $0.60-1.14$ & 1.39 & $0.81-2.39$ & 0.82 & $0.63-1.08$ & 1.32 & $0.85-2.05$ \\
\hline \multicolumn{13}{|l|}{ Triglycerides } \\
\hline Child $(<12)$ & 1.38 & $0.96-1.99$ & 1.10 & $0.81-1.48$ & 1.11 & $0.82-1.49$ & 1.14 & $0.68-1.91$ & 1.12 & $0.88-1.43$ & 1.05 & $0.73-1.52$ \\
\hline Adolescent $(\geq 12,<18)$ & 0.82 & $0.55-1.24$ & 0.96 & $0.68-1.34$ & 1.05 & $0.77-1.44$ & 1.01 & $0.59-1.71$ & 1.03 & $0.78-1.35$ & 1.17 & $0.76-1.81$ \\
\hline \multicolumn{13}{|l|}{ Glucose } \\
\hline Child $(<12)$ & 0.80 & $0.53-1.22$ & 0.70 & $0.49-1.00$ & 1.21 & $0.86-1.71$ & 0.66 & $0.35-1.25$ & 1.03 & $0.77-1.37$ & 0.77 & $0.51-1.18$ \\
\hline Adolescent $(\geq 12,<18)$ & 1.35 & $0.87-2.09$ & 1.20 & $0.84-1.74$ & 1.16 & $0.82-1.63$ & 1.33 & $0.76-2.34$ & 1.13 & $0.85-1.52$ & 1.22 & $0.75-1.97$ \\
\hline \multicolumn{13}{|l|}{ Insulin } \\
\hline Child $(<12)$ & 0.89 & $0.43-1.80$ & 0.85 & $0.48-1.51$ & 0.87 & $0.49-1.55$ & 0.92 & $0.33-2.60$ & 0.83 & $0.51-1.34$ & 1.28 & $0.64-2.56$ \\
\hline Adolescent $(\geq 12,<18)$ & 1.13 & $0.62-2.06$ & 0.90 & $0.53-1.51$ & 0.74 & $0.45-1.21$ & 0.62 & $0.29-1.33$ & 0.94 & $0.62-1.43$ & 1.36 & $0.68-2.72$ \\
\hline
\end{tabular}

height. $^{29}$ Current weight was obtained by the estimate of the participants during the interview in BBS; weight and height were used to calculate adult BMI.

PCOS was measured by using the instrument of Pederson and Corenblum, which includes four self-report questions, "Have you ever been told by a doctor that you had PCOS?", "Between the ages of 16 and 40, about how long was your average menstrual cycle?", "During your menstruating years, did you have a tendency to grow dark, coarse hair on your body?", "Between the ages of 16 and 40 , have you ever noticed a milky discharge from your nipples (not including during pregnancy or recent childbirth)?", and whether participants were obese or overweight according to their mean BMI at adult visits (Table S1), which in validation studies had a sensitivity of $77 \%$ and a specificity of $94 \% .{ }^{30}$ Smoking history was based on reporting of current and former smoking at any visit; the participants who answered "yes" to either smoking currently or formerly at any visit were coded as "ever smoked". Smoking during pregnancy was queried about each pregnancy and smoking during any trimester was counted as smoking.

Statistical analysis

Data analyses were performed by using SAS version 9.4 (SAS Institute Inc, Cary, NC)

Group comparisons were performed using $t$ tests or $x^{2}$ tests for continuous variables and categorical variables, respectively. Cochran-Armitage tests of trend were used for ordinal variables.
Multivariable logistic regression models using PROC LOGISTIC in SAS were computed to estimate odds ratios and 95\% confidence interval while controlling for covariates associated with fertility, including current age, BMl at time of measure, education level, race, and smoking history. Quadratic BMI was also included in the model as inadequate body fat may also cause subfertility. ${ }^{31,32}$ Quadratic terms for cardiovascular predictors were assessed but did not suggest nonlinear associations.

Cardiovascular risk factors were all considered as continuous predictors, and were age-standardized to $z$-score. Fertility difficulties were all considered as dichotomous variables. After analyses above, the model was repeated, excluding women who reported a diagnosis of PCOS or screened positive based on the instrument above ( $n=174,9.7 \%)$, as well as adjusting for PCOS (Tables S2 and S3).

For child participants, parental permission and assent of the child were obtained in the original study and interviews, and informed consent was obtained for adult participants. All study procedures were approved by the Institutional Review Board of Tulane University.

\section{RESULTS}

In this study, the mean current age was 45.3 years; $59 \%$ of participants were White and $41 \%$ were Black. The participants who reported ever receiving or seeking medical help to become 
Table 3. Pre-pregnant cardiovascular risk factors and infertility, the Bogalusa Heart Study

\begin{tabular}{|c|c|c|c|c|c|c|c|c|c|c|c|c|}
\hline & \multicolumn{2}{|c|}{$\begin{array}{l}\text { Ever sought } \\
\text { medical help }\end{array}$} & \multicolumn{2}{|c|}{$\begin{array}{l}\text { Ever tried but } \\
\text { unable }\end{array}$} & \multicolumn{2}{|c|}{$\begin{array}{l}\text { Unprotected } \\
\text { sex }>1 \text { year }\end{array}$} & \multicolumn{2}{|c|}{$\begin{array}{l}\text { Received medical } \\
\text { help }\end{array}$} & \multicolumn{2}{|c|}{$\begin{array}{l}\text { Any fertility } \\
\text { difficulties }^{\text {b }}\end{array}$} & \multicolumn{2}{|c|}{$\begin{array}{l}\text { Never became } \\
\text { pregnant }\end{array}$} \\
\hline & $\mathrm{OR}^{\mathrm{a}}$ & $95 \% \mathrm{Cl}$ & $\mathrm{OR}^{\mathrm{a}}$ & $95 \% \mathrm{Cl}$ & $\mathrm{OR}^{\mathrm{a}}$ & $95 \% \mathrm{Cl}$ & $\mathrm{OR}^{\mathrm{a}}$ & $95 \% \mathrm{Cl}$ & $\mathrm{OR}^{\mathrm{a}}$ & $95 \% \mathrm{Cl}$ & $\mathrm{OR}^{\mathrm{a}}$ & $95 \% \mathrm{Cl}$ \\
\hline DBP & 1.03 & $0.53-2.01$ & 1.13 & $0.67-1.90$ & 0.78 & $0.50-1.22$ & 0.99 & $0.37-2.65$ & 0.95 & $0.64-1.40$ & 1.37 & $0.77-2.44$ \\
\hline LDL & 1.03 & $0.48-2.19$ & 0.91 & $0.51-1.62$ & 0.98 & $0.60-1.59$ & 1.20 & $0.43-3.34$ & 0.96 & $0.63-1.48$ & 0.99 & $0.53-1.87$ \\
\hline Triglycerides & 0.86 & $0.42-1.75$ & 1.10 & $0.62-1.96$ & 1.42 & $0.86-2.33$ & 0.58 & $0.20-1.74$ & 1.11 & $0.72-1.72$ & 1.34 & $0.71-2.50$ \\
\hline Glucose & 2.09 & $0.95-4.59$ & 2.65 & $1.39-5.06$ & 1.02 & $0.60-1.74$ & 2.76 & $0.82-9.26$ & 1.20 & $0.76-1.91$ & 0.98 & $0.49-1.93$ \\
\hline Insulin & 1.98 & $0.75-5.21$ & 1.45 & $0.64-3.25$ & 1.08 & $0.52-2.22$ & 0.94 & $0.26-3.33$ & 1.12 & $0.61-2.06$ & 0.70 & $0.27-1.86$ \\
\hline
\end{tabular}

Table 4. Childhood cardiovascular risk factors by time period and reported fertility difficulties in adulthood, women with polycystic ovarian syndrome omitted

\begin{tabular}{|c|c|c|c|c|c|c|c|c|c|c|c|c|}
\hline \multirow[t]{2}{*}{ Cardiovascular risk factors } & \multicolumn{2}{|c|}{$\begin{array}{l}\text { Ever sought } \\
\text { medical help }\end{array}$} & \multicolumn{2}{|c|}{$\begin{array}{l}\text { Ever tried but } \\
\text { unable }\end{array}$} & \multicolumn{2}{|c|}{$\begin{array}{l}\text { Unprotected sex } \\
>1 \text { year }\end{array}$} & \multicolumn{2}{|c|}{$\begin{array}{l}\text { Received } \\
\text { medical help }\end{array}$} & \multicolumn{2}{|c|}{$\begin{array}{l}\text { Any fertility } \\
\text { difficulties }\end{array}$} & \multicolumn{2}{|c|}{$\begin{array}{l}\text { Never became } \\
\text { pregnant }\end{array}$} \\
\hline & $\mathrm{OR}^{\mathrm{a}}$ & $95 \% \mathrm{Cl}$ & $\mathrm{OR}^{\mathrm{a}}$ & $95 \% \mathrm{Cl}$ & $\mathrm{OR}^{\mathrm{a}}$ & $95 \% \mathrm{Cl}$ & $\mathrm{OR}^{\mathrm{a}}$ & $95 \% \mathrm{Cl}$ & $\mathrm{OR}^{\mathrm{a}}$ & $95 \% \mathrm{Cl}$ & $\mathrm{OR}^{\mathrm{a}}$ & $95 \% \mathrm{Cl}$ \\
\hline Child $(<12)$ & 1.00 & $0.68-1.48$ & 0.93 & $0.68-1.27$ & 1.01 & $0.75-1.36$ & 0.98 & $0.56-1.70$ & 0.91 & $0.71-1.16$ & 0.92 & $0.64-1.33$ \\
\hline Adolescent $(\geq 12,<18)$ & 1.39 & $0.94-2.05$ & 1.36 & $0.98-1.88$ & 0.96 & $0.72-1.28$ & 1.81 & $1.04-3.16$ & 1.05 & $0.82-1.35$ & 1.05 & $0.70-1.60$ \\
\hline Adolescent $(\geq 12,<18)$ & 0.92 & $0.62-1.36$ & 1.18 & $0.86-1.63$ & 0.84 & $0.63-1.11$ & 1.10 & $0.66-1.83$ & 0.90 & $0.70-1.16$ & 1.05 & $0.70-1.60$ \\
\hline \multicolumn{13}{|l|}{ LDL } \\
\hline Child $(<12)$ & 1.05 & $0.71-1.55$ & 1.14 & $0.83-1.56$ & 1.14 & $0.84-1.55$ & 1.22 & $0.67-2.22$ & 1.10 & $0.85-1.41$ & 1.41 & $0.96-2.05$ \\
\hline Adolescent $(\geq 12,<18)$ & 1.01 & $0.64-1.60$ & 0.90 & $0.62-1.31$ & 1.07 & $0.77-1.50$ & 1.23 & $0.67-2.26$ & 0.95 & $0.72-1.27$ & 1.48 & $0.92-2.38$ \\
\hline \multicolumn{13}{|l|}{ HDL } \\
\hline Child $(<12)$ & 0.91 & $0.62-1.34$ & 0.94 & $0.69-1.28$ & 1.17 & $0.86-1.58$ & 0.90 & $0.50-1.64$ & 1.05 & $0.82-1.34$ & 1.54 & $1.06-2.25$ \\
\hline Adolescent $(\geq 12,<18)$ & 1.12 & $0.71-1.77$ & 0.88 & $0.61-1.27$ & 0.87 & $0.62-1.22$ & 1.68 & $0.91-3.09$ & 0.83 & $0.62-1.11$ & 1.39 & $0.87-2.24$ \\
\hline \multicolumn{13}{|l|}{ Triglycerides } \\
\hline Child $(<12)$ & 1.42 & $0.94-2.16$ & 1.18 & $0.85-1.65$ & 1.11 & $0.80-1.53$ & 0.94 & $0.50-1.77$ & 1.10 & $0.84-1.43$ & 1.11 & $0.75-1.65$ \\
\hline Adolescent $(\geq 12,<18)$ & 1.01 & $0.65-1.57$ & 1.15 & $0.79-1.65$ & 1.09 & $0.78-1.52$ & 1.36 & $0.75-2.47$ & 1.04 & $0.78-1.39$ & 1.25 & $0.78-2.00$ \\
\hline \multicolumn{13}{|l|}{ Glucose } \\
\hline Child $(<12)$ & 1.00 & $0.62-1.63$ & 0.80 & $0.54-1.19$ & 1.33 & $0.92-1.93$ & 0.76 & $0.35-1.61$ & 1.13 & $0.83-1.54$ & 0.76 & $0.48-1.21$ \\
\hline Adolescent $(\geq 12,<18)$ & 1.28 & $0.79-2.08$ & 1.17 & $0.79-1.73$ & 1.09 & $0.75-1.59$ & 1.21 & $0.61-2.40$ & 1.07 & $0.78-1.47$ & 1.21 & $0.76-1.92$ \\
\hline
\end{tabular}

pregnant were more likely to be White and have higher education (Table 1). The majority of participants of this study had been pregnant $(88.6 \%)$ and had at least one live birth (85.8\%). Women with a history of PCOS were also more likely to report fertility difficulties. All indicators of infertility were strongly correlated with each other $(p<0.01)$. Of those who reported never having been pregnant, 63 (32\%) reported ever trying but not being able to become pregnant, vs. 252 (16\%) of those who had been pregnant at least once.

Childhood and adolescent cardiovascular risk factors were generally not associated with fertility indicators (Table 2), although childhood LDL (aOR 1.38 per 1-SD unit, 0.97-1.96) and total cholesterol (aOR 1.49 per 1-SD unit, 1.06-2.11) were raised in those who never became pregnant. Childhood glucose was 
Table 5. Pre-pregnancy cardiovascular risk factors and reported fertility difficulties in adulthood without polycystic ovarian syndrome

\begin{tabular}{|c|c|c|c|c|c|c|c|c|c|c|c|c|}
\hline & \multicolumn{2}{|c|}{$\begin{array}{l}\text { Ever sought } \\
\text { medical help }\end{array}$} & \multicolumn{2}{|c|}{$\begin{array}{l}\text { Ever tried but } \\
\text { unable }\end{array}$} & \multicolumn{2}{|c|}{$\begin{array}{l}\text { Unprotected } \\
\text { sex }>1 \text { year }\end{array}$} & \multicolumn{2}{|c|}{$\begin{array}{l}\text { Received medical } \\
\text { help }\end{array}$} & \multicolumn{2}{|c|}{$\begin{array}{l}\text { Any fertility } \\
\text { difficulties }^{\mathrm{b}}\end{array}$} & \multicolumn{2}{|c|}{$\begin{array}{l}\text { Never became } \\
\text { pregnant }\end{array}$} \\
\hline & $\mathrm{OR}^{\mathrm{a}}$ & $95 \% \mathrm{Cl}$ & $\mathrm{OR}^{\mathrm{a}}$ & $95 \% \mathrm{Cl}$ & $\mathrm{OR}^{\mathrm{a}}$ & $95 \% \mathrm{Cl}$ & $\mathrm{OR}^{\mathrm{a}}$ & $95 \% \mathrm{Cl}$ & $\mathrm{OR}^{\mathrm{a}}$ & $95 \% \mathrm{Cl}$ & $\mathrm{OR}^{\mathrm{a}}$ & $95 \% \mathrm{Cl}$ \\
\hline DBP & 1.00 & $0.48-2.08$ & 1.14 & $0.65-2.02$ & 0.75 & $0.47-1.19$ & 0.61 & $0.18-2.06$ & 0.92 & $0.61-1.37$ & 1.38 & $0.76-2.50$ \\
\hline LDL & 0.82 & $0.35-1.91$ & 0.78 & $0.42-1.46$ & 0.93 & $0.56-1.54$ & 0.73 & $0.21-2.55$ & 0.90 & $0.58-1.40$ & 0.86 & $0.45-1.67$ \\
\hline Triglycerides & 0.71 & $0.30-1.66$ & 1.03 & $0.54-1.96$ & 1.41 & $0.84-2.37$ & 0.55 & $0.15-2.05$ & 1.06 & $0.67-1.68$ & 1.22 & $0.62-2.40$ \\
\hline Glucose & 1.52 & $0.61-3.78$ & 2.24 & $1.18-4.28$ & 0.97 & $0.55-1.69$ & 1.86 & $0.57-6.12$ & 1.08 & $0.66-1.75$ & 0.96 & $0.46-2.0 \mathrm{i} 0$ \\
\hline
\end{tabular}

Results of logistic regression; estimates adjusted for education level, race, tobacco use history and BMI at time of measure, and BMI-squared $S B P$ systolic blood pressure, $D B P$ diastolic blood pressure, $H D L$ high-density lipoprotein, $L D L$ low-density lipoprotein

protective (aOR, 0.70, 0.49-1.00). Precision followed sample size, so the most precise estimates were for blood pressure, and childhood estimates were generally a bit more precise than adolescent. Pre-pregnancy risk SBP (any fertility difficulties, aOR 1.49 per 1-SD unit, 1.00-2.23) and glucose levels (ever tried but unable, aOR 2.65 per 1-SD unit, 1.39-5.06) were associated with an increased risk of some infertility indicators (Table 3 ). Again, the associations with blood pressure were measured most precisely. These results were largely unaffected by exclusion of women with PCOS (Tables 4 and 5); indeed, the associations between SBP as an adolescent became stronger (e.g., aOR 1.81 per 1-SD unit, 1.04-3.16 for receiving medical help) and HDL as an adolescent was protective (aOR for any fertility difficulties $0.70,0.53-0.94$ ).

\section{DISCUSSION}

This study investigated lifetime cardiometabolic risk as a predictor of fertility, which is seldom studied in a life-course perspective. Overall, few associations were seen, although overall cholesterol, blood pressure, and glucose were associated with indicators of infertility in some analyses. The results were generally similar when women with PCOS were omitted, and some cases were strengthened.

Few previous studies have addressed the relationship between CVD risk factors and fertility. Pugh et al. reported a $19-36 \%$ decrease in fecundability associated with abnormal lipoprotein levels $;^{9}$ this is in the range of the associations we saw between pre-pregnancy cholesterol and triglycerides and never becoming pregnant (although our associations are not as precise). Schisterman et al. and Verit et al. also found reductions in fecundity with higher lipids, although the type of analysis makes comparisons of effect size difficult. ${ }^{10,33}$ Some previous work has addressed infertility as a predictor of later or concurrent CVD, rather than vice versa. Swedish studies showed that women reporting subfertility for $\geq 5$ years had a $20 \%$ increased risk of incident CVD compared with women reporting no history of subfertility, while subfertility $<5$ years was not related to CVD; ${ }^{12}$ similarly, women who had used in vitro fertilization had a higher incidence of later hypertension. ${ }^{13}$

Several mechanisms could link cardiovascular risk and infertility in women. Women with PCOS have higher levels of LDL-C, triglycerides, and lower levels of HDL-C compared with control groups. ${ }^{34}$ In addition, infertility related to PCOS is correlated with increased waist circumference, insulin resistance (IR), and higher lipoprotein ratios (TG/HDL-C) compared to healthy controls. ${ }^{35}$ However, most of the associations remained even after women with PCOS were removed from analysis or when PCOS was adjusted for (data not shown), despite the association between PCOS and the fertility markers. This suggests either that the PCOS effects on fertility are mediated through other pathways (such as endocrine pathways), or that women who sought medical attention for fertility were more likely to be diagnosed with PCOS. Cardiovascular risk markers are increased in young women with diminished ovarian reserve ${ }^{33}$ and primary ovarian insufficiency, ${ }^{36}$ both of which are linked to infertility. Furthermore, endometriosis, which is found in $5-10 \%$ of infertile women, is also related to CVD. ${ }^{37}$ PCOS, endometriosis, and CVD are all associated with inflammation. ${ }^{38}$ Other possible links include hypertension (pregnancy-induced or nonpregnancy-induced), and early miscarriages due to hypercoagulable states/thrombophilia, ${ }^{39}$ associated with excess CVD risk. ${ }^{40}$

A major strength of the present investigation is that we examined cardiovascular risk factors, prospectively obtained since childhood. This minimizes recall bias, and our questionnaire data allow statistical control for several important confounders, including age, race, smoking history, education level, and current BMI. Statistical power was provided by more than 600 women with subfertility. In addition, our analysis includes women who never became pregnant, so the associations are not conditioned on eventual fertility.

Assessment of fertility difficulties was based on self-report. Selfreport of ever becoming pregnant or having a baby should be accurate. Reports were consistent between different indicators of infertility and overall pregnancy history, and correlated among each other, though not identical. The sample was communitybased, including both African-American and white women, unlike many studies of fertility, which tend to be conducted among those seeking treatment. Such self-report includes women who met the clinical definition for infertility, but never sought treatment. Thus, we have a more generalizable study than those predicated on seeking medical advice. Also, many of the included women became pregnant before ART was common. In addition, this study used several fertility-related questions as surrogates of subfertility. Still, self-report of fertility issues is subject to misclassification, ${ }^{41}$ and we have no information on specific clinical diagnoses or possible causes of infertility, which could include partner's infertility rather than conditions related to the women. Likewise, PCOS was also self-reported (although with a validated questionnaire) and tends to be underdiagnosed; therefore, a certain amount of PCOS cases may have been missed. The large number of comparisons made false positives a possibility, and, indeed, there are one or two protective associations as well. Finally, adult height, and thus adult BMI, was estimated for much of the cohort.

In conclusion, this study suggests a degree of association between pre-pregnancy cardiovascular health and fertility outcomes, but little for earlier life. Further studies are necessary to explore the association using both clinical and prospective 
measurements of fertility, as well as the intermediate factors studied. If verified, this suggests that interventions to improve cardiovascular health might also improve fertility.

\section{ACKNOWLEDGEMENTS}

The Bogalusa Heart Study is supported by National Institutes of Health grants R01HD069587, AG16592, HL121230, HD032194, and P50HL015103.

\section{ADDITIONAL INFORMATION}

The online version of this article (https://doi.org/10.1038/s41390-018-0032-x) contains supplementary material, which is available to authorized users.

Competing interests: The authors declare no competing interests.

Publisher's note: Springer Nature remains neutral with regard to jurisdictional claims in published maps and institutional affiliations.

\section{REFERENCES}

1. Chandra, A., Copen, C. E., \& Stephen, E. H. Infertility and impaired fecundity in the United States, 1982-2010: data from the National Survey of Family Growth. Natl Health Stat. Report 1-18 (1 p following 19) (2013).

2. Homan, G. F., Davies, M. \& Norman, R. The impact of lifestyle factors on reproductive performance in the general population and those undergoing infertility treatment: a review. Hum. Reprod. Update 13, 209-223 (2007).

3. Ray, A., Shah, A., Gudi, A. \& Homburg, R. Unexplained infertility: an update and review of practice. Reprod. Biomed. Online 24, 591-602 (2012).

4. Quaas, A. \& Dokras, A. Diagnosis and treatment of unexplained infertility. Rev. Obstet. Gynecol. 1, 69-76 (2008).

5. Lane, M., Zander-Fox, D. L., Robker, R. L. \& McPherson, N. O. Peri-conception parental obesity, reproductive health, and transgenerational impacts. Trends Endocrinol. Metab. 26, 84-90 (2015).

6. Jacobs, M. B., Bazzano, L. A., Pridjian, G., \& Harville, E. W. Childhood adiposity and fertility difficulties: the Bogalusa Heart Study. Pediatr. Obes. 12, 477-484 (2017).

7. Wise, L. A., Palmer, J. R. \& Rosenberg, L. Body size and time-to-pregnancy in black women. Hum. Reprod. 28, 2856-2864 (2013).

8. Sundaram, R., Mumford, S. L. \& Buck Louis, G. M. Couples' body composition and time-to-pregnancy. Hum. Reprod. 32, 662-668 (2017).

9. Pugh, S. J. et al. Preconception maternal lipoprotein levels in relation to fecundability. Hum. Reprod. 32, 1055-1063 (2017).

10. Schisterman, E. F. et al. Lipid concentrations and couple fecundity: the LIFE study. J. Clin. Endocrinol. Metab. 99, 2786-2794 (2014).

11. Verit, F. F., Yildiz Zeyrek, F., Zebitay, A. G. \& Akyol, H. Cardiovascular risk may be increased in women with unexplained infertility. Clin. Exp. Reprod. Med. 44, 28-32 (2017).

12. Parikh, N. I., Cnattingius, S., Mittleman, M. A., Ludvigsson, J. F. \& Ingelsson, E. Subfertility and risk of later life maternal cardiovascular disease. Hum. Reprod. 27 568-575 (2012).

13. Westerlund, E. et al. Incidence of hypertension, stroke, coronary heart disease, and diabetes in women who have delivered after in vitro fertilization: a population-based cohort study from Sweden. Fertil. Steril. 102, 1096-1102 (2014).

14. Berenson, G. S., Srinivasan, S. R. \& Bao, W. Precursors of cardiovascular risk in young adults from a biracial (black-white) population: the Bogalusa Heart Study. Ann. N. Y. Acad. Sci. 817, 189-198 (1997).

15. McGill, H. C. Jr, McMahan, C. A., Malcom, G. T., Oalmann, M. C. \& Strong, J. P. Effects of serum lipoproteins and smoking on atherosclerosis in young men and women. The PDAY Research Group. Pathobiological Determinants of Atherosclerosis in Youth. Arterioscler. Thromb. Vasc. Biol. 17, 95-106 (1997).

16. El Hayek, S., Bitar, L., Hamdar, L. H., Mirza, F. G. \& Daoud, G. Polycystic ovarian syndrome: an updated overview. Front. Physiol. 7, 124 (2016).
17. March, W. A. et al. The prevalence of polycystic ovary syndrome in a community sample assessed under contrasting diagnostic criteria. Hum. Reprod. 25, 544-551 (2010)

18. Joham, A. E., Boyle, J. A., Zoungas, S. \& Teede, H. J. Hypertension in reproductiveaged women with polycystic ovary syndrome and association with obesity. Am. J. Hypertens. 28, 847-851 (2015).

19. Diamanti-Kandarakis, E., Spritzer, P. M., Sir-Petermann, T. \& Motta, A. B. Insulin resistance and polycystic ovary syndrome through life. Curr. Pharm. Des. 18, 5569-5576 (2012).

20. Orio, F., Palomba, S., \& Colao, A. Cardiovascular risk in women with polycystic ovary syndrome. Fertil. Steril. 86, S20-S21 (2006).

21. Birdsall, M. A., Farquhar, C. M. \& White, H. D. Association between polycystic ovaries and extent of coronary artery disease in women having cardiac catheterization. Ann. Intern. Med. 126, 32-35 (1997).

22. Berenson, G. S. et al. Association between multiple cardiovascular risk factors and atherosclerosis in children and young adults. The Bogalusa Heart Study. N. Engl. J. Med. 338, 1650-1656 (1998).

23. Dick, M. L. et al. Self-reported difficulty in conceiving as a measure of infertility. Hum. Reprod. 18, 2711-2717 (2003).

24. Herbert, D., Lucke, J. \& Dobson, A. Agreement between self-reported use of in vitro fertilization or ovulation induction, and medical insurance claims in Australian women aged 28-36 years. Hum. Reprod. 27, 2823-2828 (2012).

25. Joffe, M. Methods for obtaining valid data on time to pregnancy among men and women. Scand. J. Work. Environ. Health 25, 8-9 (1999).

26. Zielhuis, G. A., Hulscher, M. E. \& Florack, E. I. Validity and reliability of a questionnaire on fecundability. Int. J. Epidemiol. 21, 1151-1156 (1992).

27. Cooney, M. A., Buck Louis, G. M., Sundaram, R., McGuiness, B. M. \& Lynch, C. D. Validity of self-reported time to pregnancy. Epidemiology 20, 56-59 (2009).

28. Berkey, C. S. et al. Longitudinal height velocity standards for U.S. adolescents. Stat. Med. 12, 403-414 (1993).

29. Paley, J. et al. The multiplier method for prediction of adult height. J. Pediatr Orthop. 24, 732-737 (2004).

30. Pedersen, S. D., Brar, S., Faris, P. \& Corenblum, B. Polycystic ovary syndrome: validated questionnaire for use in diagnosis. Can. Fam. Physician 53, 1042-1047 (2007). 1041.

31. Davies, M. J. Evidence for effects of weight on reproduction in women. Reprod. Biomed. Online 12, 552-561 (2006).

32. Frisch, R. E. Body fat, menarche, fitness and fertility. Hum. Reprod. 2, 521-533 (1987).

33. Verit, F. F., Keskin, S., Omer, B., Yalcinkaya, S. \& Sakar, N. Is there any relationship between cardiovascular risk markers and young women with diminished ovarian reserve? Gynecol. Endocrinol. 30, 697-700 (2014).

34. Talbott, E. et al. Coronary heart disease risk factors in women with polycystic ovary syndrome. Arterioscler. Thromb. Vasc. Biol. 15, 821-826 (1995).

35. Ghaffarzad, A., Amani, R., Mehrzad Sadaghiani, M., Darabi, M. \& Cheraghian, B. Correlation of serum lipoprotein ratios with insulin resistance in infertile women with polycystic ovarian syndrome: a case control study. Int. J. Fertil. Steril. 10, 29-35 (2016).

36. Wellons, M. Cardiovascular disease and primary ovarian insufficiency. Semin. Reprod. Med. 29, 328-341 (2011).

37. Wise, J. Women with endometriosis show higher risk for heart disease. BMJ 353 i1851 (2016).

38. Vannuccini, S. et al. Infertility and reproductive disorders: impact of hormonal and inflammatory mechanisms on pregnancy outcome. Hum. Reprod. Update 22 104-115 (2016).

39. Sotiriadis, A., Makrigiannakis, A., Stefos, T., Paraskevaidis, E. \& Kalantaridou, S. N. Fibrinolytic defects and recurrent miscarriage: a systematic review and metaanalysis. Obstet. Gynecol. 109, 1146-1155 (2007).

40. Chan, M. Y., Andreotti, F. \& Becker, R. C. Hypercoagulable states in cardiovascular disease. Circulation 118, 2286-2297 (2008).

41. Guzick, D. S. et al. Infertility evaluation in fertile women: a model for assessing the efficacy of infertility testing. Hum. Reprod. 9, 2306-2310 (1994). 